\title{
CONGENITAL ANEURYSMS OF ALL THREE SINUSES OF VALSALVA
}

\author{
BY \\ R. H. MICKS \\ From Sir Patrick Dun's Hospital, Dublin \\ Received August 25, 1939
}

Aneurysm of a single sinus of Valsalva, though rare, is not so rare as to justify a detailed description of a single case. For it is recognized that both syphilis and ulcerative endocarditis may produce aneurysms or aneurysmal dilatations of the sinuses, and the causation is not obscure. In a small number of such aneurysms no evidence of these two causes has been found and it has been suggested that they may be congenital ; at least eleven such cases have been recorded, mostly involving the right (or anterior) sinus only.

But aneurysms of all three sinuses of Valsalva are extremely rare. I have been able to find records of only three such cases, and comparison of these with the one here reported suggests that it presents a condition that has not been recorded previously.

\section{Clinical Notes of the Terminal Illness}

The patient was a young man, aged 25 , well built and of healthy appearance. His family doctor had for some time known that he had an enlarged heart and a systolic apical murmur, but these signs had been discovered in a routine examination and he had never complained of any symptoms that could be attributed to the heart. He was accustomed to cycle in all weathers and played golf without breathlessness or fatigue.

About a month before his admission to hospital, when pushing a lawnmower on his holiday, he collapsed with pain in the chest, shortness of breath, and a feeling of great weakness. He stayed in bed six days, but on getting up had a similar attack and was again in bed a few days. On returning to his office work he felt as well as ever for a few days.

July 12, 1938.- - He awoke early in the morning one hour after falling asleep, with a feeling of heat, of pain referred to the region of the xiphoid, of cough, and of shortness of breath. His doctor found an irregular pulse of over 100, a temperature of $101^{\circ} \mathrm{F}$., and crackles over the apex of the right lung.

The same evening he was admitted to Sir Patrick Dun's Hospital under the author's care. His general condition was little changed. The pain was referred to the upper abdomen a little to the left of the midline. The apex beat was felt in the left anterior axillary line and there was a systolic murmur 
heard best at the apex. The heart rate was 50 and slightly irregular, and the blood pressure was $130 / 60$. The liver was enlarged and palpable one or two inches below the costal margin. The spleen was not to be felt. The temperature was still $101^{\circ}$ and the respiration rate 46 .

Both pleural spaces were explored under local anæsthesia, no fluid being found. The pericardial sac also was punctured in the region of the left ventricle. Digoxin, $0.5 \mathrm{mg}$. intravenously, produced no change in the heart rate. No other drug of the digitalis group was administered, then or previously. It is hardly likely that this single dose of digoxin can have played any part in producing the disturbances of heart rhythm subsequently recorded. The tentative diagnosis at this stage was an acute infective process, but next day it was recognized as cardiac failure due to a gross disturbance of rhythm.

July 13.-The patient slept lightly, thanks to an injection of $1 / 8$ grain of morphine, and was much the same. A blood culture proved to be sterile. The Wassermann reaction was negative. Hæmoglobin, 70 per cent. ; red cells, $4,800,000$; white cells, 17,000 . The heart rate was 40 in the morning and 35 by the evening.

There was total heart block (A, $100 ; \mathrm{V}, 40$ to 50). The ventricular complexes were prolonged beyond $0 \cdot 1 \mathrm{sec}$. and there were many right ventricular extrasystoles (Fig. 1A).

July 14.-There was a marked change for the worse, the patient appearing

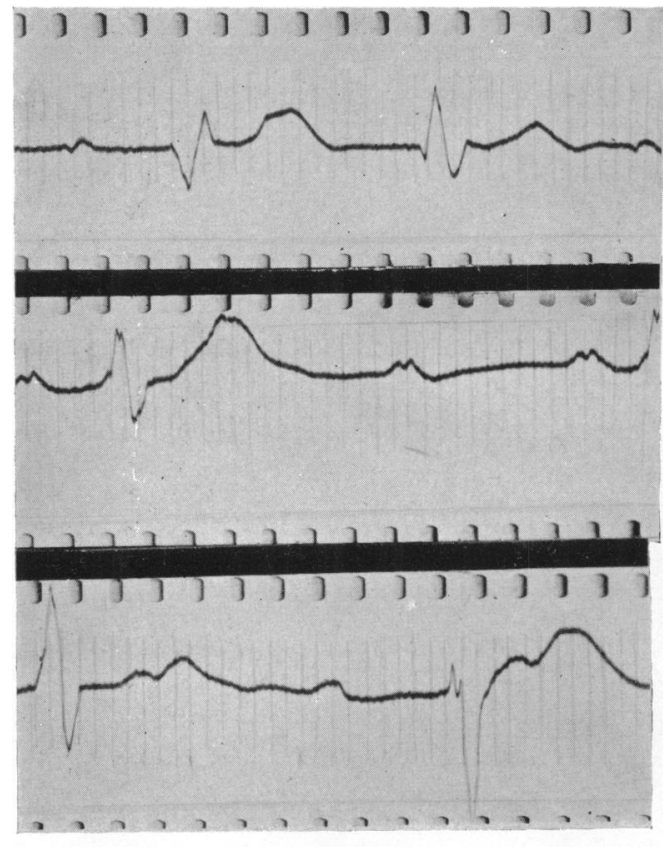

A

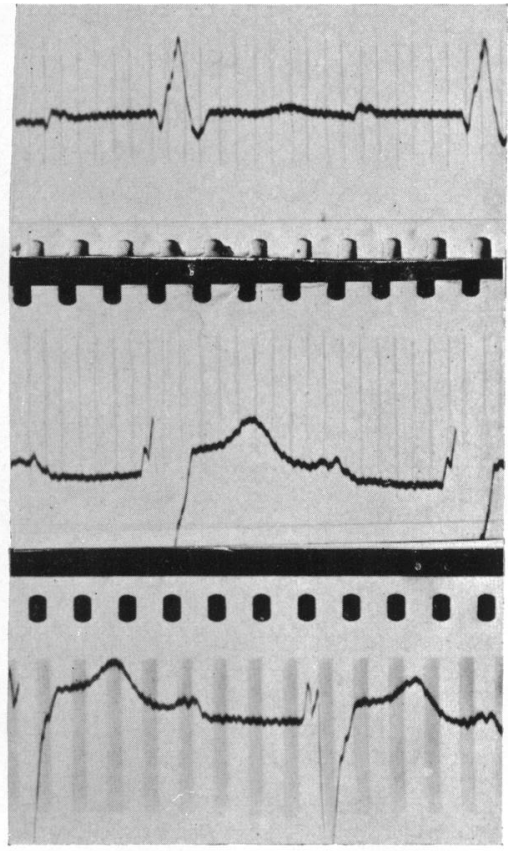

B

Fig. 1.

(A) July 13. Total heart block. Auricular rate 100, ventricular rate 40-50.

(B) July 15. Regular sinus rhythm. Rate 68. Left ventricular preponderance. 
on the verge of death. Adrenaline was given for the first time, with good effect. After $2.5 \mathrm{mg}$. the rate rose from 25 to 75 , and the blood pressure from $125 / 50$ to $135 / 75$. After two and a half hours the rate had fallen to 36 , and $1.0 \mathrm{mg}$. of adrenaline was given, again with good effect. After a third injection of $1.0 \mathrm{mg}$. adrenaline, when the rate had again fallen to 32 , it rose only to 52 , but was maintained at 48 .

A dramatic change for the better took place that evening, probably owing to a return of sinus rhythm. At 9 the heart rate was 52 , at 9.40 it was 124 , and at 10 it was 114 ; the patient said he was very much better and it almost seemed that the illness was over.

July 15.-After a good night with the help of $1 / 8$ grain of morphine, he still felt very well. The heart rate was 79 and the pulse strikingly dicrotic, this being so pronounced that it was hard to tell by palpating the radial artery whether the heart rate was 80 or 160 . The blood pressure readings of this dicrotic pulse were: systolic a little over 120 and diastolic between 70 and 75 . It is interesting to speculate on the possibility of a connexion between the gross abnormality subsequently found in the patient's heart and the presence of this very remarkable dicrotic pulse on the only day when we had an opportunity of observing the patient with the heart rhythm normal.

The liver was still enlarged. The apex beat was diffuse and reached two inches outside the nipple line in the 5th and 6th spaces. There was a snappy first sound and faint (non-crescendo) pre-systolic and systolic murmurs, with no thrill. There was no œdema. As there were no physical signs of disease in the lungs and the presence of a cardiac lesion of radiological interest was not suspected, radioscopy was postponed to avoid tiring the patient ; but next day he was too weak, so the opportunity of securing an X-ray picture of a very rare abnormality was missed.

The heart rate did not vary throughout the day and the patient's condition remained good. There was regular sinus rhythm, with a P-R interval of $0 \cdot 3 \mathrm{sec}$. The QRS complexes were more than $0 \cdot 1 \mathrm{sec}$. and resembled the extrasystoles of the first electrocardiogram (Fig. 1B).

July 16.-The patient had not had a good night and was worse. During the night the pulse rate had been variable and settled at a lower level-74, 52 . $40,52,72$, and at 9.30 between 48 and 52, and slightly irregular. At 11 a.m, $1.0 \mathrm{mg}$. of adrenaline produced a rise from 36 to 54 and also a rise of blood pressure from $110 / 40$ to $140 / 60$.

Fig. 2A, 105 minutes after the adrenaline, showed total heart block. The auricular rate was now 210 , and the $P$ waves differed greatly from those in Fig. 1. The ventricular complexes now showed left ventricular preponderance, and $T_{3}$ was deeply inverted. Presumably the rhythm was auricular flutter or auricular paroxysmal tachycardia.

During the remainder of this day adrenaline was given on several occasions and relieved the patient considerably, but his condition at the best was far more grave than on the previous day.

July 17.-The patient was still gravely ill. During the night adrenaline was given twice, when the rate dropped below 40 . 
Total block was present at noon, 9 and 14 hours after administration of adrenaline and of ephedrine respectively. The auricular rate was 210 . Flattening of all the $T$ waves as compared with the previous day was noted (Fig. 2B).

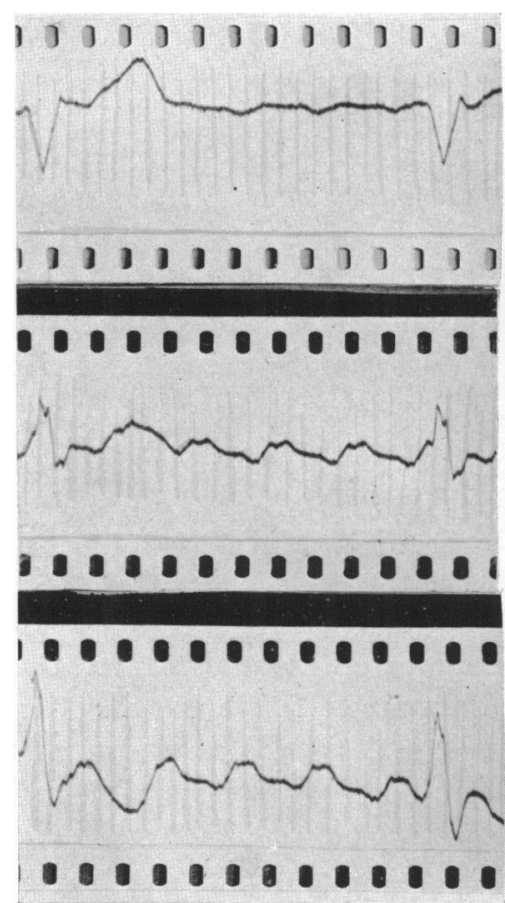

A

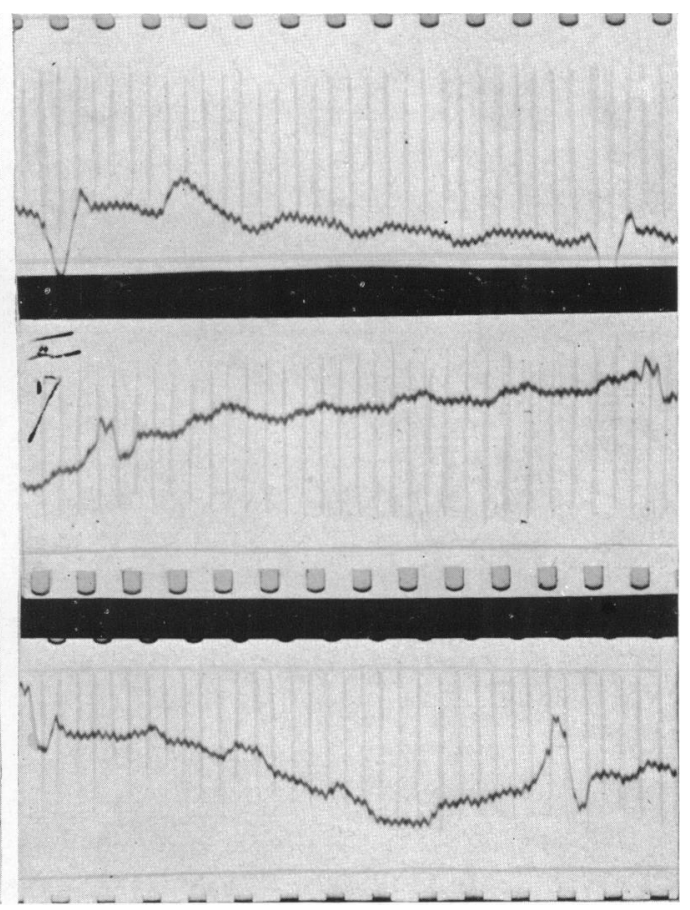

B

Fig. 2.-Complete heart block. Auricular rate 210.

(A) July 16. 105 minutes after adrenaline. $P$ waves greatly differing from those of Fig. 1A. Presumably auricular flutter or auricular paroxysmal tachycardia.

(B) July 17. No adrenaline in preceding 9 hours. Note flattening of all $T$ waves in comparison with (A).

During the day the rate varied from 38 to 52 and no ephedrine or adrenaline was given. At 6 p.m. the rate was 40 and $1 / 2$ grain of ephedrine was given. Ten minutes later the rate was 114 and the patient was feeling better. Nevertheless he was still gravely ill.

July 18.-During the previous night the rate had varied between 120 and 148 , and no drugs had been given except $1 / 8$ grain of morphine early in the night.

Fig. $3 \mathrm{~A}$, taken at 10.30 , showed a regular ventricular rate of 138 . The new change of the QRS complexes should be noted, $P_{1}$ being still inverted. The rhythm seemed to be $2: 1$ heart block in auricular flutter or tachycardia.

At 5 p.m. the rate was still fast, 128 , but four hours later it was 62 . Ephedrine, 1/4 grain, was then given orally, a rise to 74 following. Fig. 3B, taken soon after, showed what appeared to be an auricular tachycardia of the same rate as before, now with a $4: 1$ ventricular response.

July 19.-The patient's condition was not such as to give rise to acute 
anxiety till 9 a.m., when he became dyspnœic. The rate was then 46 , a rate which had been noted frequently throughout the night without concomitant dyspnœa. Ephedrine and adrenaline relieved the dyspnœa slightly, although

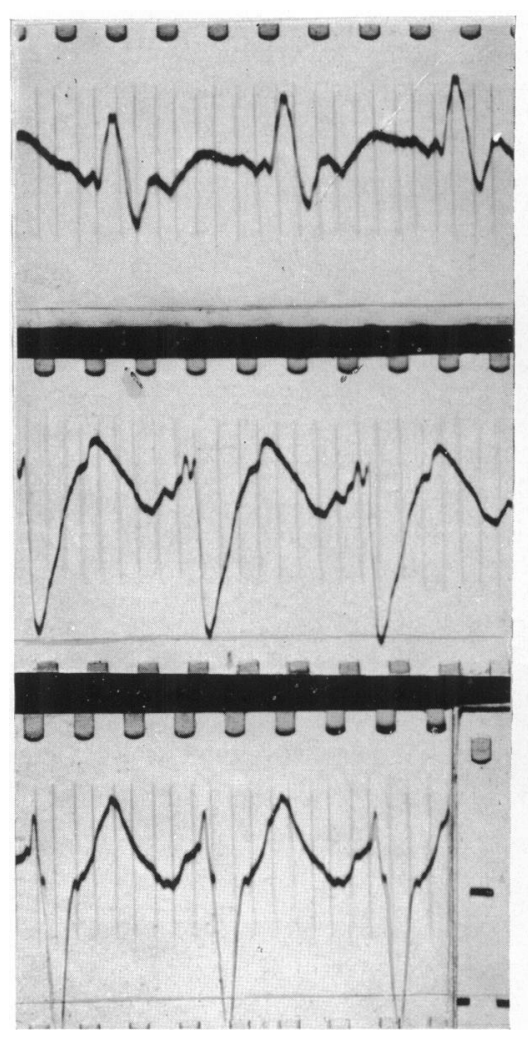

A

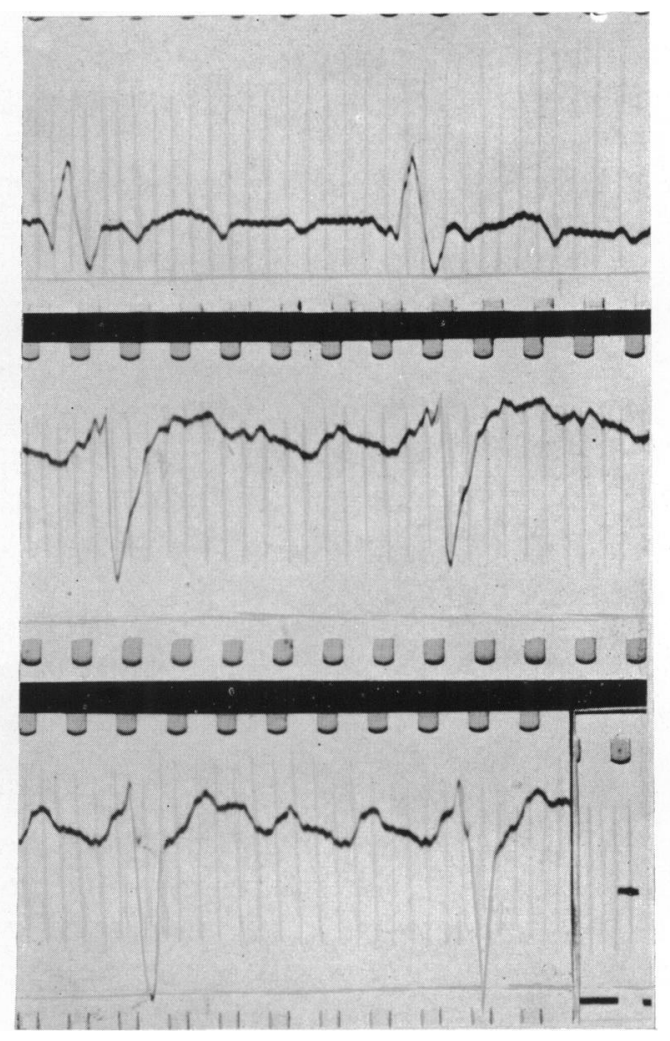

B

FIG. 3.

A) July 18. No drugs except morphine in preceding 30 hours. Regular ventricular rate of 138. $P_{1}$ still inverted. Note new change of QRS complexes. Query, 2:1 heart block in auricular tachycardia or flutter.

(B) July 18. Just after pulse had been raised from about 62 to about 74 by ephedrine. Apparently auricular tachycardia of same rate as (A), now with a $4: 1$ ventricular response.

the rate increased only from 40 to 48 . At 11 he was still dyspnœic; the heart rate was 50 , very irregular and hard to count even by auscultation. Repeated injections of adrenaline and ephedrine were given without benefit. At 2.50 p.m. the rate was recorded for the last time as 32 , and at 3 p.m. the patient died.

\section{Autopsy}

A complete autopsy was not made, but the thoracic viscera were removed. The lungs showed congestion only. The heart and pericardium were removed intact and placed in preservative. Some time later the pericardium was 
opened and an abnormal prominence to the left of the pulmonary artery was noted, but the cavities of the heart were not opened until the main trunks of the coronary arteries had been dissected out throughout their superficial course and found to be normal.

When the cavities of the heart were opened the three dilated pockets or aneurysms of the sinuses of Valsalva were at once apparent. They were filled with some recent soft blood-clot. There was also a considerable amount of old brown blood-clot, fairly firmly adherent to the inner walls of the sinuses, and this was picked off with a dissecting forceps.

\section{Nomenclature of THE AORTIC CUSPS}

When the left ventricle is opened out, the use of such terms as " right," "left," "anterior," and " posterior" as descriptions of the aortic cusps and the sinuses that lie behind them may be confusing. The cusps are most readily identified by the mouths of the coronary arteries and the simplest method of description would be that of right coronary, left coronary, and noncoronary cusps. For that reason we have used a terminology that corresponds closely to this and for the sake of convenience we append the following glossary :

The right aortic cusp is the cusp behind which the right coronary artery arises. It is also known as the anterior aortic cusp (British Revision, 1933).

The left aortic cusp is the cusp behind which the left coronary artery arises. It is also known as the left posterior aortic cusp (B.R.).

The posterior aortic cusp is the cusp behind which no coronary artery arises. It is also known as the right or right posterior aortic cusp (B.R.)

\section{Description of the HeART}

The heart was large, weighing 750 grammes. After it had been freely opened it was found to measure externally $14.5 \mathrm{~cm}$. from base to apex by $13 \cdot 2 \mathrm{~cm}$. from side to side.

The pericardium was normal in appearance except for a small patch of fibrinous pericarditis at the apex, the result of the exploratory puncture made seven days before death.

The coronary arteries had been dissected out throughout their course outside the heart muscle before the cavities of the heart were opened. They could be seen lying free from overlying connective tissue and were normal in appearance.

The only striking abnormality to be seen from outside was the large prominence (well shown in Fig. 4) lying to the left of the pulmonary artery.

The wall of the right auricle was $0.3 \mathrm{~cm}$. thick, and of the left $0.3 \mathrm{~cm}$. thick. The wall of the right ventricle was $0.5 \mathrm{~cm}$. thick, and that of the left from 1.5 to $2.0 \mathrm{~cm}$. at its thickest.

The cavities of the auricles and of the right ventricle were normal, except for the bulges to be seen on the ventricular walls of the auricles and the septal 
wall of the right ventricle. There was no defect of the inter-auricular septum ; no evidence of endocarditis, past or recent, on either walls or valves ; and no thinning of the walls at any of the points where they were deformed by the bulges. The pulmonary and tricuspid valves were normal ; also the cusps of the mitral valve ; but the mitral opening, $9.5 \mathrm{~cm}$. in circumference, was considerably stretched and probably incompetent during life.

Inspection of the cavity of the left ventricle showed that each sinus of Valsalva was expanded to a large aneurysm or pouch. A detailed description

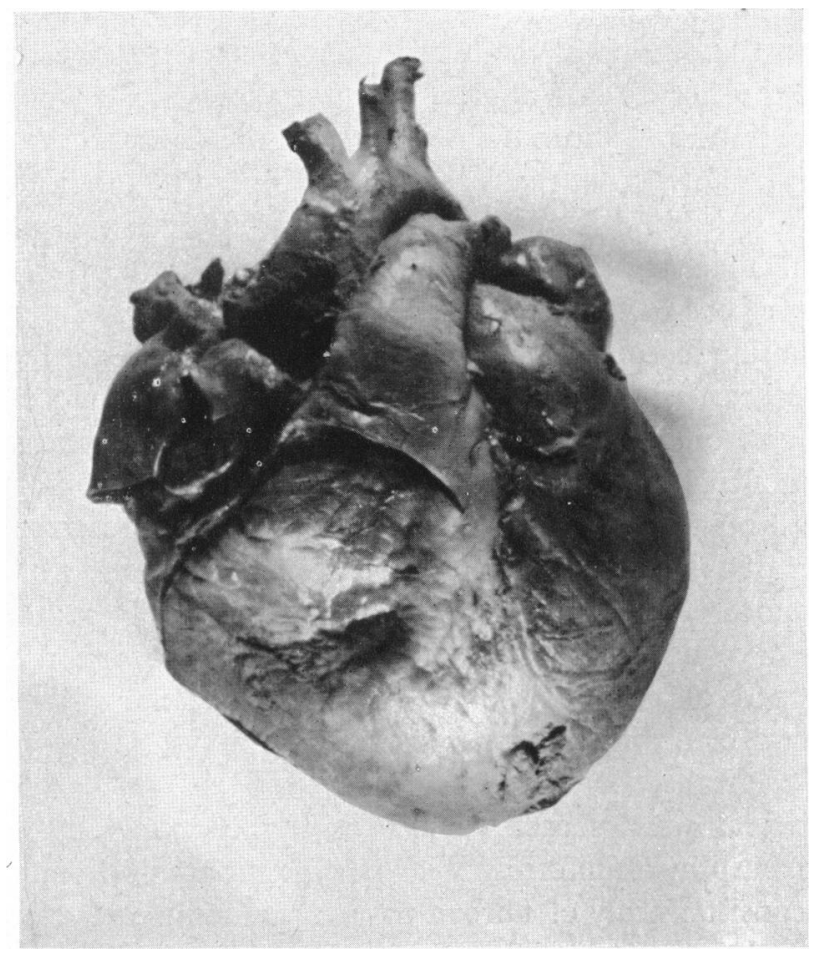

FIG. 4.-External view of the heart. Cavities had already been incised, but the outline was restored so far as possible. Arch of the aorta seen at the top. Below it the pulmonary artery. Beside it part of the left ventricle, showing protrusion of the aneurysm of the left sinus (slightly overlapped by the left auricular appendage). The root of the aorta is not shown.

of each aneurysm will be given, but a brief general description should make it easier to understand the anomaly.

The cavity of the left ventricle is described by anatomists as consisting of two parts : the main body of the ventricle with trabeculated walls; and the aortic vestibule, that part of the cavity lying immediately below the aortic cusps, with smooth non-trabeculated walls. Normally this aortic vestibule forms a small part of the cavity, being a shallow irregular collar less than $1 \mathrm{~cm}$. in depth. In the hypertrophied left ventricle this collar may be deeper.

The abnormality found in our specimen consists in this, that the aortic 
vestibule was considerably larger than normal, measuring $5.0 \mathrm{~cm}$. from the free edge of the semilunar cusps to the upper edge of the trabeculated portion of the ventricular cavity, and was excavated by three pockets, measuring from 3.0 to $4.9 \mathrm{~cm}$. in depth, which were extensions downwards of the sinuses of Valsalva.

Only one of these pockets deformed the outer aspect of the heart, that one being the aneurysm of the left sinus of Valsalva; it forms the bulge visible in Fig. 4 to the left of the pulmonary artery. The other pockets produced no prominence on the outside of the heart.

This observation, that only the aneurysm of the left sinus produced a prominence on the outside of the heart, demonstrates that the aneurysms are dilatations of the sinuses of Valsalva, and not aneurysms of the aorta above the level of the sinuses. For in the normal heart the sinuses of Valsalva belong to the part of the aortic root that is entirely embraced by the heart wall except at one place, just to the left of the pulmonary artery, where a part of the left sinus of Valsalva is supported only by the wall of the aorta.

The cavity of each aneurysm was lined to a large extent by endocardium, which was continuous on the ventricular wall of the cavity (the "anterior" wall when the heart is opened out, as in Fig. 5) with the endocardium of the aortic cusps, and on the aortic (or " posterior") wall with the intima of the aorta. Much of each cavity was lined by brown adherent blood-clot, and when this was picked off the endocardial lining underneath was seen to be replaced by what appeared to be fibrous tissue. So large a portion of each cavity possessed a smooth endocardial lining that it seems probable that the endocardium may once have been continuous over the whole inner wall and that it was destroyed only by organization of blood clots. Removal of the organized blood clot with a dissecting forceps did not in any place disclose a thinning of the wall underneath.

The ventricular wall of each cavity was formed partly by its own cusp, and below the cusp by a uniformly thick partition (about $0 \cdot 1 \mathrm{~cm}$. thick), which appeared to consist mainly of fibrous tissue. Laterally each cavity narrowed considerably and was separated from its neighbour by a similar partition. The other (non-ventricular) wall of each cavity was formed by the adjacent portion of the myocardium, and the myocardial wall of the cavities did not appear to be eroded or thinned.

The photograph (Fig. 5) shows the interior of the left ventricle, opened by an incision passing through the aorta at the junction of the left with the posterior aortic cusp. The left auricle too is shown opened out and the cusps of the mitral valve can be seen. The arch of the aorta can be identified by its three large branches, and the two coronary orifices can be seen. On the extreme left of the picture part of the cavity of the left auricle can be seen. Next from the left can be seen the cavity of the large left sinus of Valsalva cut across by the incision ; this has just opened the posterior margin, and so a very small part of the cavity is seen on the right of the picture as well (Fig. 5F) just above the attachment of the aortic cusp of the mitral valve. To the right of this is the mouth of the left sinus, the left aortic cusp being pulled upwards 
and to the left by the traction on the heart wall required to display the specimen for photography ; the opening of the left coronary artery is clearly seen. To the right again, in the centre of the picture, is seen the mouth of the right sinus (Fig. 5D), with the opening of the right coronary artery just above it. Finally, beside it, is the mouth of the posterior sinus (Fig. 5E) ; both this and the right sinus have been lightly packed with cotton wool for

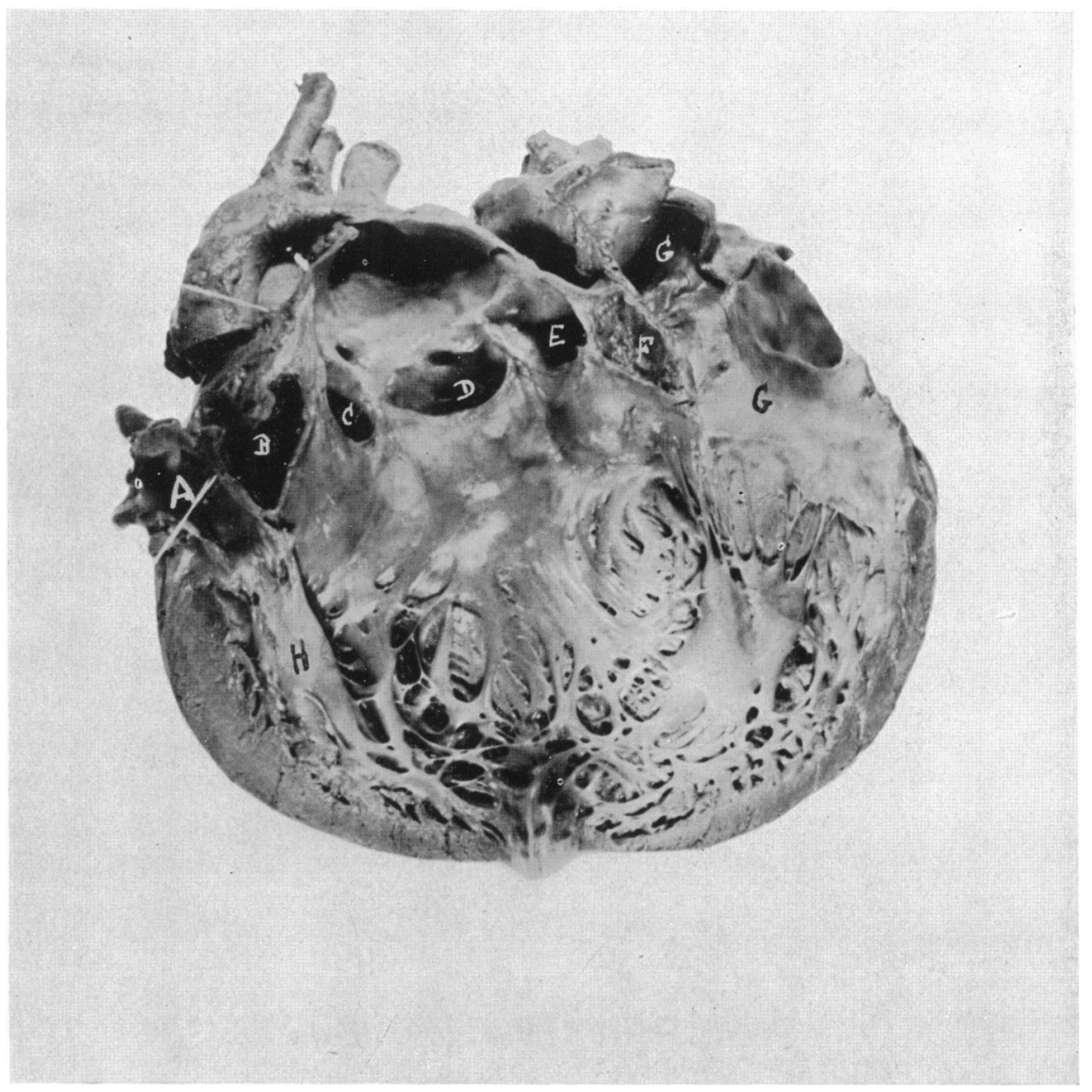

Fig. 5.--Interior of left ventricle.

(A) Part of left auricle. (B) Cavity of left sinus cut across. (C) Opening of left sinus with orifice of left coronary artery just above. (D) Opening of right sinus with orifice of right coronary artery just above. (E) Opening of posterior sinus. (F) Cavity of left sinus cut across (corresponds to (B) ). (G) Cavity of left auricle. (H) Anterior papillary muscle. The inferior papillary muscle is seen opposite (H) and below (G).

photographic purposes. To the right again is the mitral valve and the left auricle.

The intima of the aorta is smooth and normal in appearance, but a few yellow streaks are seen about the opening of the right coronary artery. The circumference of the aorta at this level is $7.7 \mathrm{~cm}$. 
The three aortic cusps are visible, and behind each cusp is the opening into a grossly dilated sinus of Valsalva, each of these openings measuring about $2.5 \mathrm{~cm}$. in diameter when the tension on the walls of the opened ventricle is relaxed enough to allow them to assume a roughly circular form. The width of the openings is not so great as the length of the aortic cusps, for each opening is separated from its neighbour by a roughly pyramidal buttress over $1.0 \mathrm{~cm}$. thick at its base, to which the aortic cusps are attached. Similar buttresses may be seen serving as the points of attachment of the aortic cusps in many hearts in which the left ventricle is considerably enlarged. They are well shown in the photograph, the buttress between the right sinus and the posterior sinus standing out particularly clearly; the buttress between the right sinus and the left sinus is less striking; that between the left sinus and the posterior sinus can be recognized on the right of the photograph by the attachment of the aortic cusp of the mitral valve.

The ends of the aortic cusps are attached to the buttresses springing from the aorta. Thus the aortic cusps lie at a lower level than normal, being in fact over $1.0 \mathrm{~cm}$. lower than the openings of the coronary arteries. The upper level of each buttress lies at about the normal level of the point of attachment of the aortic cusps. In the case of the buttress lying between the posterior and the right sinuses the cusp is continued along the upper aspect of the buttress as a fold of endocardium, which suggests that the low position of the cusps may be the result of traction. The cusps of the pulmonary artery are normal in position, i.e. $1.0 \mathrm{~cm}$. higher than the aortic cusps.

\section{The Posterior Sinus of Valsalva}

The posterior (right posterior, B.R.) aortic cusp is of normal thinness, but it alone presents one slight abnormality. The posterior sinus is separated from the anterior by a thick buttress. Similar buttresses exist at the other two points of junction, and in the case of the other two sinuses the aortic cusps are attached to the tip of the buttresses ; but, in the case of the posterior aortic cusp, the end of the cusp that is related to the anterior aortic sinus does not end at its point of attachment to the buttress, but is prolonged along the superior surface of the cusp as a shallow fold of endocardium to the aortic attachment of the buttress. This fold of endocardium is so shallow (under $1 \mathrm{~mm}$. in depth) that it can only just be picked up with the fingers; its length is $1.4 \mathrm{~cm}$. The cusp proper is $2.8 \mathrm{~cm}$. in length, and the corpus Arantii is situated in the middle of the cusp proper, and not in the middle of the $4.2 \mathrm{~cm}$. long fold of cusp proper plus endocardial fold.

The cavity of the posterior sinus is roughly spherical and 9 c.c. in volume. Its depth, measured from the free margin of the aortic cusp, is from 3.0 to $3.5 \mathrm{~cm}$. It is separated from the right sinus and from the left sinus by thick buttresses. It is related anteriorly to that smooth-walled part of the cavity of the left ventricle known as the aortic vestibule, and posteriorly it bulges into both right and left auricles. It also bulges slightly into the right sinus of Valsalva. 
The orifice of the posterior sinus differs from the orifices of the other sinuses in that it is constricted by a thick semilunar fold, less than $1.0 \mathrm{~cm}$. below the aortic cusp. The base of this fold is about $1.0 \mathrm{~cm}$. in length and is attached to the buttress that separates the posterior from the left sinus. The free margin is directed to the right, is about $1.0 \mathrm{~cm}$. distant from the base, and shows a very slight concavity. This fold constricts the orifice of the posterior sinus to a diameter of about $1.0 \mathrm{~cm}$. Below this fold the sinus expands to a cavity of approximately $2.5 \mathrm{~cm}$. in diameter.

\section{The Right Sinus of Valsalva}

The right (anterior, B.R.) aortic cusp is of normal thinness and the corpus Arantii can be felt half-way along its free margin, which measures $4 \cdot 1 \mathrm{~cm}$. in length.

The opening of the right coronary artery may be seen above the right aortic cusp. It is a little less than $1.0 \mathrm{~cm}$. above the plane marking the opening of the sinus, and cannot be described as lying within the sinus. It lies $2 \cdot 2 \mathrm{~cm}$. from the junction of the right and left aortic cusps and $1.7 \mathrm{~cm}$. from the junction of the right and posterior aortic cusps. It is $2.9 \mathrm{~cm}$. from the orifice of the left coronary artery. Its orifice is of normal size, and a few faint yellow streaks (but not wrinkles) around it suggest a slight degree of atheroma.

The cavity of the right aortic sinus measures 15 c.c. in volume. Its outline is that of a waistcoat pocket that tapers slightly towards its depth, the greatest depth being $4.0 \mathrm{~cm}$. The cavity has a ventricular aspect related to the smoothwalled aortic vestibule of the left ventricle; the other aspect is related to both the right auricle and the right ventricle, and it produces very striking prominences on the walls of those chambers. The cavity of the right sinus occupies the whole of the inter-ventricular septum above the level of the line of junction of the aortic vestibule with the main body of the ventricle; the dilated sinus is in such a position that it would seem to have interfered with the bundle of His, where it straddles the interventricular septum (the pars membranacea), dividing there into right and left branches. Yet there is no thinning of the sinus wall to be detected at this point, alluded to by authors, who have reported cases of aneurysm of the right sinus, as a locus minoris resistentice.

The ventricular wall of the sinus is formed above by the aortic cusp, which is of approximately normal thinness and depth; at the attached border of the aortic cusp a sudden transition in thickness is to be noted where the cusp gives place to the thicker sinus wall ; this wall appears to be mostly fibrous, but streaks of reddish strands (presumably muscle fibres) can be seen running up into it from the main body of the ventricular wall below.

\section{The Left Sinus of Valsalva}

The left (left posterior, B.R.) aortic cusp is of normal thinness, and the corpus Arantii can be felt half-way along its free margin. As the ventricle 
was open by a cut that divided the aorta close to the cusp, this is more curled on itself than the other two. When straightened by gentle traction its free margin measured $3.7 \mathrm{~cm}$.

The dilated left sinus of Valsalva is by far the most striking of the three " aneurysms," for it is the largest and is also the only one that is directly related to the external surface of the heart ; it forms the prominence so clearly seen in Fig. 5 to the left of the pulmonary artery.

It would have been almost impossible to have opened the left ventricle without opening up one of the sinuses in some place, and fortunately the incision does not pass across the middle of the cavity, but opens it at its extreme posterior border near the aortic cusp of the mitral valve.

The volume of the left sinus is hard to measure owing to the incision made, but it holds over 50 c.c. and probably between 60 and 70 c.c. The greatest depth of the cavity is $4.9 \mathrm{~cm}$. and its greatest breadth $6.9 \mathrm{~cm}$. It extends downwards from the free margin of the left aortic cusp to about the line of junction between the aortic vestibule and the main body of the ventricle. Internally it is related to the cavity of the left ventricle. Externally it bulges into the pericardial sac to the left of the pulmonary artery. It is not related to any of the other chambers of the heart, but it extends the whole way across the upper part of the left ventricle from the inter-ventricular septum in front and to the right to the attachment of the aortic cusp of the mitral valve behind and to the left.

The orifice of the left coronary artery lies a little above the point of junction of right and left aortic cusps, being thus outside the sinus.

I have presented the clinical and anatomical record of this unusual case as fully and accurately as I can, and leave it for those who are competent to discuss it. The term " congenital aneurysm "was used in the title of this paper, because I cannot think of any morbid process capable of producing the condition described after the stage of development is past.

\section{DisCUSSION}

In most text-books aneurysm of the sinuses of Valsalva receives only the briefest mention, and the usual causes described are syphilis and ulcerative endocarditis. I have not attempted to survey the subject of aneurysms of the aorta involving one or more of the sinuses of Valsalva, but only those communications that record an abnormal dilatation of all three sinuses.

Instances of presumed congenital aneurysm of one sinus have been recorded, the sinus affected being in nearly every case the right (or anterior) sinus. These aneurysms are discussed by Maude Abbott (1927 and 1932). Henke and Lubarsch (1924) also devote several pages to the subject. 
I have been able to find only three records of cases with aneurysms or pathological dilatations of all three sinuses, those of Carpentieri (Naples), of Barnscheidt (Bonn), and of Habán (Budapest).

Carpentieri's case (1912).- The patient died after an illness of four days. He was 45 years old and a deaf-mute, so that it was difficult to take a history of the illness. He was too sick for thorough examination, but œedema of both lower limbs was recorded. The apex beat was $3.0 \mathrm{~cm}$. outside the midclavicular line in the sixth space. There was a presystolic-systolic murmur audible at the apex and a systolic murmur at the aortic area. There was no record of the heart rhythm.

The heart was enlarged, measuring $12.0 \mathrm{~cm}$. at its base by $12.7 \mathrm{~cm}$. in its greatest length. The left ventricle, which was responsible for most of the enlargement, was enormously dilated; its walls were $2.3 \mathrm{~cm}$. thick, and the mitral orifice was dilated and admitted three fingers easily, but was not incompetent, in Carpentieri's opinion, as the dilatation was compensated for by the length of the cusps.

The aortic cusps were thickened and shortened by "atheromatous scars," but the aortic orifice was nevertheless normal. The aorta itself showed "atheromatous scars."

The three sinuses of Valsalva were represented by three large cavities, but their position is obviously different from that in our specimen, for they are described as presenting swellings about the size of a nut on the exterior of the aorta. Another important difference is that the lower limit of each cavity was formed by the attachment of the cusp, whereas in our specimen the cusps are attached to the anterior wall of the cavity, which extends downwards about $4 \mathrm{~cm}$. below the level of their free margin. Neither the relations nor the size of the three sinuses were carefully described, but the left was mentioned as being the largest and as excavating a small tract of the upper wall of the left ventricle. The walls of the sinuses, especially of the left, were very thin (sottilissime).

No abnormal communication existed between the chambers of the heart, or between the aorta and pulmonary artery.

There was, in the author's opinion, no evidence of syphilis ; but the patient died early in 1911, and apparently no test was done on his serum ; the " atheromatous scars" described on the aorta and the aortic cusps should be noted.

Barnscheidt's case (1920). - This has not been published, but is mentioned by Henke and Lubarsch. The specimen was described by Barnscheidt in 1920. I wish to express my gratitude to the authorities of the Bonn University Library for their great courtesy in lending me the thesis presented by Dr. Barnscheidt for his doctor's degree.

The heart was a museum specimen, the clinical history of which was not 
known. It was described as " relatively small." The wall of the left ventricle had a greatest thickness of $1.9 \mathrm{~cm}$. and an average thickness of $1.4 \mathrm{~cm}$. The aorta was healthy and the aortic orifice had a circumference of $5.3 \mathrm{~cm}$. The myocardium and endocardium appeared healthy.

The aortic cusps were unusually thin and shiny and greatly altered in configuration through the part which they took in forming the aneurysms. Each sinus showed a marked dilatation (eine erhebliche Ausbuchtung), the depth of the right and posterior sinuses being about $1 \mathrm{~cm}$., while that of the left sinus was less. In all three sinuses the direction of the dilatation was sideways and horizontal, but also downwards in the direction of the left ventricle. The surfaces of contact of the cusps were thus increased in breadth to about $4 \mathrm{~mm}$. On the inferior margin of these surfaces a swelling about $2 \mathrm{~mm}$. thick had formed, on which slight verrucosities were to be found. These changes were best marked on the posterior cusp.

The dilatations were not all of the same volume; the posterior sinus was the largest, the right was slightly smaller, while the left was considerably smaller with a depth of only about $0.5 \mathrm{~cm}$. measured horizontally. No perforations were present.

Barnscheidt gave it as his opinion that the aortic valve cannot have been incompetent; the possibility of some degree of aortic stenosis cannot, he thinks, be so readily denied, as the aneurysmal sacs hanging down into the left ventricle may well have given rise to some narrowing of the aortic orifice. The endocardial changes on the inferior surfaces of the aortic cusps must have been secondary.

Barnscheidt gave no measurements apart from those we have quoted, but the thesis contains a photograph of the specimen that suggests that the " aneurysms" were very small. The heart was a formalin-specimen in the museum and the difficulties of examining and photographing such an old hardened preparation must have been very great.

Habán's case (1937).-A man, aged 46, was admitted to St. Stephan Hospital in Budapest three days after duodenal perforation. He died some hours after operation. Nothing was reported about his previous history.

The heart showed syphilitic changes confined to the sinuses of Valsalva and the aortic cusps, but Habán holds (with reason, we think, judging by his description) that the syphilitic process was not the cause of the aneurysms, and that an abnormal dilatation of all three sinuses must have already been present. The degree of dilatation was slight, the right sinus being the largest ; it was described as being large enough to admit completely the terminal phalanx of the thumb. The posterior sinus was the next largest, and the left sinus the smallest, being described as markedly larger than normal. 
SUMMARY

1. A case is described in which aneurysms, or more correctly gross dilatations, of all three sinuses of Valsalva were present.

2. The left ventricle was considerably hypertrophied, but apart from this and the aneurysms the heart was healthy. There was no evidence of syphilis or endocarditis, recent or old-standing. There were no perforations or abnormal communications between the chambers of the heart.

3. The aneurysms were deep (nearly $5.0 \mathrm{~cm}$.) pocket-like extensions of the sinuses of Valsalva in a downward direction. They excavated the smoothwalled part of the ventricle described as the aortic vestibule, but not the thick trabeculated portion of the wall. Their symmetry, their endocardial lining, and the absence of syphilitic or ulcerative changes were strongly suggestive of a congenital abnormality.

4. The aneurysm of the left sinus measured over 60 c.c. in volume. It formed a prominence on the surface of the heart to the left of the pulmonary artery.

5. The aneurysm of the right sinus measured 15 c.c. in volume. It bulged into both the right auricle and the right ventricle. The presence of this aneurysm in the interventricular septum is believed to have produced the heart-block from which the patient died.

6. The aneurysm of the posterior sinus measured 9 c.c. in volume. It bulged into both the right and left auricles.

7. The patient was free from symptoms of heart disease tily a few months before his death. He died from acute cardiac failure and complete heart block, and during his last illness several interesting disturbances of rhythm occurred.

8. Records of three other cases of aneurysm of all three sinuses of Valsalva have been found and discussed. In all the degree of dilatation was considerably less than in the case here recorded, and the direction of the excavation appears to have been different.

I am indebted to my medical colleague, Dr. J. A. Wallace, for his help with the clinical aspect of the case and for the electrocardiographic examinations and reports. Dr. J. Kay Jamieson and Dr. R. G. Inkster devoted much time and trouble to dissecting and photographing the specimen, and I owe much to their advice and help.

I wish also to thank Dr. Maude Abbott, Dr. Wardrop Griffith, and Dr. C. P. Martin, whose replies to my letters asking for help contained so many useful suggestions.

I acknowledge my gratitude to the authorities of the Bonn University Library for their great courtesy in lending me the thesis presented by Dr. Barnscheidt for his doctor's degree. 


\section{REFERENCES} Barnscheidt, K. (1920). Inaug. Diss. (Bonn). Not published. In the University Library,
Bonn.

Carpentieri, T. (1912). Riforma Med., 31, 841.

Habán, G. (1937). Ztschr. f. Kreislaufforschung, 29, 74.

Henke und Lubarsch (1924). Handb. d. spez. path. Anat. u. Histol., 2, 227 and 749.

Nelson (1932). Nelson's Loose-Leaf Medicine, p. 271.

Osler and McCrae (1927). Modern Medicine, p. 711. 